PHYSICAL REVIEW D 96, 079901(E) (2017)

\title{
Publisher's Note: Ideal relativistic fluid limit for a medium with polarization [Phys. Rev. D 96, 056012 (2017)]
}

David Montenegro, Leonardo Tinti, and Giorgio Torrieri

(Received 2 October 2017; published 16 October 2017)

DOI: 10.1103/PhysRevD.96.079901

This paper was published online on 18 September 2017 with an omission in the Acknowledgments. "This work is a part of the project INCT-FNA Proc. No. 464898/2014-5" has been added to the Acknowledgments as of 2 October 2017. The Acknowledgments are correct in the printed version of the journal. 